Resenha

\title{
Somos o que Lembramos e Também o que Resolvemos Esquecer
}

\author{
Memória \\ Iván Izquierdo \\ Porto Alegre: Artmed, 2011, 133 p.
}

Lidiomar José Mascarello

${ }^{\mathrm{I}}$ Universidade Federal de Santa Catarina

Ivan Izquierdo nasceu em Buenos Aires em 1937. Formou-se em Medicina. Doutor pela Universidade de Buenos Aires. Tornou-se professor titular na Universidade de Córdoba. Vive no Brasil. Foi contratado, inicialmente, pela Universidade Federal do Rio Grande do Sul e, mais recentemente, pela Pontifícia Universidade Católica do Rio Grande do Sul. Suas linhas de pesquisa: mecanismos bioquímicos da formação, expressão, extinção e reconsolidação de memórias; mecanismos moleculares de plasticidade sináptica; e alteraçôes na memória com o envelhecimento normal e na Doença de Alzheimer.

A obra intitulada Memória, a qual me proponho resenhar, tem como objetivo principal apresentar informaçóes sobre aspectos básicos das estruturas cerebrais, seus funcionamentos, as estruturas neuronais e os processos sinápticos envolvidos nas bases biológicas da memória. É uma obra que, além de informativa, apresenta resultados e reflete 40 anos de pesquisa e estudos dedicados a este tema.

O livro está organizado em dez capítulos. $\mathrm{O}$ primeiro - $\mathrm{O}$ que é memória? - apresenta definiçôes e defende que memória significa aquisição, formação, conservação e evocação de informações e que é este processo, ou o acesso a este "banco de dados" (acervo das memórias) de cada um, que nos converte em indivíduos. Nele ainda são encontradas noçôes sobre os neurônios, sua organização, estrutura e funcionamento.

No capítulo 2 - Tipos e formas de memória são apresentadas a organização e a nomenclatura mais aceita atualmente sobre os tipos de memória dos indivíduos, sendo primeira a memória de trabalho, que serve para "gerenciar a realidade". O autor defende também que estes tipos variam de acordo com o seu conteúdo, podendo ser declarativas e procedurais, e com o tempo, podem ser de curta e longa duração ou, ainda, remotas. No 3 - Os mecanismos da formaçáo das memórias —, trata dos mecanismos fisiológicos e moleculares da formação ou consolidação das memórias, enquanto no 4 - As memórias de curta e de longa duraçáo — fala sobre quais processos estão envolvidos na consolidação da memória ou na sua perda e não consolidação e qual o papel das memórias. Já no 5 - Persistência das memórias de longa duração - relaciona a persistência da memória ao alto grau de alerta emocional envolvido. No 6 - Evocaçáo, extinção e reconsolidação das memórias - menciona que nem sempre conseguimos lembrar ou evocar determinadas coisas ou aspectos de determinados eventos. Segundo o autor, é consenso entre os pesquisadores da área que "as memórias são armazenadas através de modificaçóes, da forma e da função das sinapses das redes neurais de cada memória” (p. 79).

No sétimo capítulo - A modulação das memórias: influência do nível de alerta, do nível de ansiedade e do estado de ânimo —, é defendido que tanto os estados de ânimo quanto as emoçóes, a atenção/alerta, a ansiedade e o estresse influenciam fortemente as memórias. $\mathrm{O}$ capítulo 8 - Síndromes amnésicas e hipermnésicas - menciona que para se evitar o esquecimento, ou a diminuição de trocas sinápticas, é necessário manter alto grau de exercitabilidade das áreas cerebrais, pois na visão de Izquierdo "a função faz o órgão". O nono - As demências - explica que esta doença é diagnosticada por conta de perdas significativas de neurônios que abrangem as funçôes superiores, e o último - Temas variados - apresenta resultados de vários estudos $\mathrm{e}$ informaçóes relevantes sobre aspectos da memória, como, por exemplo, lesóes cerebrais em crianças.

Diante do conteúdo da obra, podemos nos questionar: o que seria de nós sem memória? Conseguiríamos pentear o cabelo, escovar os dentes, caminhar, sair e voltar para casa diariamente? $\mathrm{Ou}$ 
teríamos que aprender isso a cada dia, como se fosse algo novo? É a formação, a conservação, a evocação e a manutenção da informação que nos faz ser o que somos. É graças à memória que cada ser humano é quem é. "A coleção de lembranças de cada indivíduo é distinta das demais", bem como seu esquecimento (p. 12).

A forma que cada sujeito recebe, percebe, codifica, armazena, acessa e recupera a informação, que se dá de modo serial, paralelo e independente, é particular. E ainda que nem todas as memórias estejam disponíveis para serem evocadas, conscientemente lembradas, podemos recuperar somente aquilo que foi registrado, o que foi aprendido ou apreendido. Sendo assim, se somos o que recordamos, não podemos ser, nem fazer, o que desconhecemos, tampouco enunciar ou dizer aquilo que náo dispomos.

Entretanto, esta individualidade não nos garante plena sobrevivência. Não vivemos bem isoladamente; necessitamos formar grupos e interagir. Para isso, criamos laços de sangue, laços culturais, laços por afinidade e outros mais, tendo por base memórias que, de alguma forma, são compartilhadas, o que nos dá certa segurança, suporte e identidade coletiva. A noção de estado e país também é fruto de lembranças e está intimamente ligada à memória, portanto, temos um acervo histórico comum a todos. Além disso, temos uma identidade individual que depende da história de cada um.

Segundo Izquierdo (p. 19), tanto a nossa memória pessoal quanto a coletiva descartam o trivial e, ainda, por vezes incorpora fatos irreais. Ao longo do tempo vamos perdendo aquilo que náo nos interessa, o que é menos marcante, e ao mesmo tempo incorporamos mentiras e variaçóes de eventos.

A memória é organizada segundo a função que desempenha, com o tempo de duração e seu conteúdo. Sendo assim, a memória de trabalho é a que "gerencia a realidade”, isto é, mantém a informação que está sendo processada. É a que nos possibilita saber onde estamos e o que estamos fazendo a cada momento. Em outras palavras, dá continuidade aos nossos atos.

Outras memórias são as que registram eventos ou conhecimentos. Elas são denominadas declarativas e podem ser episódicas ou autobiográficas. E existem também as de conhecimentos gerais ou semânticas, além das de procedimentos, divididas entre implícitas e explícitas.

Em relação à formação e ao funcionamento das memórias, Izquierdo (p. 13 a 18) afirma que as memórias são feitas de células nervosas, os neurônios, que se organizam e armazenam em redes, e ativadas pelas mesmas ou outras redes, sendo o estado de ânimo, as emoçóes e o nível de consciência responsáveis, em grande parte, pela regulaçáo desse processo.

E como a memória é criada? Sabe-se que as memórias não são adquiridas ou formadas imediatamente na sua forma final, pelo contrário, até a sua consolidação acontece uma série de processos metabólicos no hipocampo e em outras estruturas áreas cerebrais. Nessas estruturas ocorrem processos eletrofisiológicos denominados potenciação de longa duração, conhecidos também como "etiquetamento sináptico" (p. 50). Em outras palavras, as memórias contam com conexóes temporárias ou permanentes entre os neurônios.

O livro dedica muitas páginas às estruturas fisiológicas da formação das memórias e descreve com detalhes as trocas sinápticas entre os neurônios e o funcionamento de cada neurotransmissor, além de como estas cadeias são geradas. Esse processo denomina-se base biológica da formação das memórias. $\mathrm{O}$ que temos no cérebro na verdade são proteínas em ação. É possível prever quantas trocas sinápticas são necessárias para que ocorra uma retenção de informação, ou para que o indivíduo guarde determinada memória? Segundo Izquierdo, sim, desde que saibamos a que tipo de memória estamos nos referindo. Se for algo simples, como, por exemplo, esquiva, são necessários alguns milhóes de sinapses em seis ou sete regiôes cerebrais. Já se for uma memória semântica complexa, haverá envolvimento de vários bilhôes de sinapses e muitas áreas cerebrais.

E por que se denominam basicamente as memórias como de curta duração, longa duração e memória de trabalho? Qual a base biológica ou quais as evidências para tais afirmaçôes? Izquierdo conta que é possível demonstrar que as bases bioquímicas e a farmacologia molecular são distintas entre si, e que vários experimentos apresentam que é viável tratar cada uma em particular. Entretanto, muitas vezes ocorre que mais de uma memória pode ser afetada ao mesmo tempo caso haja algum comprometimento ou dano cerebral.

Outro aspecto importante é a evocação das memórias. No momento das lembranças há a reativação das redes sinápticas, o que nos permite criar, fantasiar, reorganizar.

Além de lembrar ou relembrar é igualmente importante esquecer. Esquecer faz parte de uma 
memória saudável; é como se o cérebro fizesse uma seleção do que é relevante e necessário ser guardado. Entretanto, essa seleção não é tão livre assim. Ela é fortemente influenciada pelos níveis de alerta e ansiedade, pelo estado de ânimo e estresse, dentre outro fatores fisioquímicos aos quais estamos expostos diariamente. Esse fenômeno também é conhecido como dependência de estado endógena e serve de modulador das memórias. E há ainda esquecimentos considerados naturais, provocados pela senilidade.

Diferente do esquecimento natural, a memória pode sofrer danos causados por diversos fatores, como, por exemplo, lesão cerebral ou simplesmente a diminuição das sinapses. Outras situações que podem provocar amnésia são os distúrbios afetivos, principalmente a depressão, entretanto, é a esquizofrenia a maior vilá da memória, seguida bem de perto pelas doenças de Alzheimer e de Parkinson.

Finalizo dizendo a todos os curiosos e, principalmente, a estudantes das áreas médicas, áreas afins ou áreas que façam alguma interface com a medicina, psicologia ou biologia, que esse livro atinge o objetivo a que se propóe: apresentar informaçóes sobre aspectos básicos das estruturas cerebrais, seus funcionamentos, as estruturas neuronais e os processos sinápticos envolvidos nas bases biológicas da memória. A leitura é agradável e de fácil entendimento.

\section{Referência}

Izquierdo, I. (2011). Memória. Porto Alegre: Artmed. 